\title{
Experienciação, cognição e representações da memória: uma análise discursiva do patrimônio imaterial da Região dos Inconfidentes
}

Experienciation, cognition and representations of memory: a discursive analysis of immaterial heritage in the Inconfidentes Region

\author{
Paulo H. A. Mendes \\ Universidade Federal de Ouro Preto \\ Simone P. S. Mendes ${ }^{1}$ \\ Universidade Federal de Ouro Preto
}

Resumo

O presente artigo tem como objetivo apresentar as primeiras reflexões acerca da pesquisa que estamos desenvolvendo sobre o patrimônio imaterial da Região dos Inconfidentes, a partir de um conjunto de entrevistas com moradores de Passagem de Mariana, MG, coletadas ao longo de 2012. Num primeiro momento, fizemos uma apresentação da metodologia utilizada na coleta das entrevistas, para, em seguida, construirmos uma abordagem conceitual das relações entre memória, cognição e discurso, fundamentada em categorias oriundas de diferentes quadros teóricos, a exemplo de noções como "experienciação discursiva" (AUCHLIN, 2008), "performance e vocalidade" (ZUMTHOR, 1987), "memória cognitivo-discursiva" (PAVEAU, 2007), "espaço semiótico" (BRANDT, 2004), entre outras. Para efeito de ilustração dessa abordagem, analisamos um pequeno excerto de uma das entrevistas realizadas, com vistas a exemplificar o desenvolvimento de um dos tópicos-guias que nortearam a realização da pesquisa.

Palavras-chave

Patrimônio Imaterial, Experienciação Dialogada, Representações da Memória. 


\section{Abstract}

This article aims at presenting the first thoughts of a research we are carrying out on the Immaterial Heritage of the Inconfidentes Region, on the basis of various interviews with inhabitants of Passagem de Mariana (Minas Gerais - Brazil), collected in 2012. At first, we presented the methodology used for collecting the interviews, then we built up a conceptual approach to the relationship between memory, cognition and discourse, based on categories derived from different theoretical frames, such as the notions of "discursive experienciation" (AUCHLIN, 2008), "performance and vocality" (ZUMTHOR, 1987), "cognitive-discursive memory" (PAVEAU, 2007), "semiotic space" (BRANDT, 2004), amongst others. To illustrate this approach, we analyzed a small excerpt of one of the interviews carried out in order to exemplify one of the guiding topics employed in the research.

\section{Keywords}

Immaterial Heritage, Dialogical Experienciation, Representations of Memory. 


\section{Introdução}

Nosso artigo é fruto das primeiras reflexões acerca do patrimônio imaterial da Região dos Inconfidentes, tomando como base um conjunto de entrevistas com moradores de Passagem de Mariana-MG, coletadas ao longo do ano de 2012, nesse mesmo Distrito de Mariana. Essas entrevistas integram parte das atividades previstas no projeto de pós-doutorado, intitulado "Memórias marianenses: uma análise discursiva da experienciação dialogada". ${ }^{2}$ Neste artigo, desenvolvemos uma abordagem articulada ao projeto "Cognição, memória e linguagem: uma visão integrada entre as práticas discursivas e os acervos da Região dos Inconfidentes"3, cujo escopo teórico-metodológico serviu de base para o tratamento conceitual e analítico das entrevistas aqui apresentado.

Os referidos projetos ${ }^{4}$ apresentam como um dos seus objetivos a constituição de um Banco de Dados que se coloque na perspectiva de ampliação da pesquisa e do conhecimento científico de questões regionais e dos seus impactos na constituição das ideias de patrimônio cultural, nação e construção do imaginário coletivo, no que tange aos Estudos da Linguagem, numa perspectiva teórica transdisciplinar. Os esforços dos pesquisadores do GEDEM na construção do Banco de Dados estão direcionados a acervos representativos do Patrimônio Material da Região dos Inconfidentes, bem como do seu Patrimônio Imaterial, tal como descreveremos a seguir.

O Instituto de Ciências Humanas e Sociais da Universidade Federal de Ouro Preto está inserido em uma região privilegiada, entre outros fatores, pela riqueza de seu acervo cultural ainda pouco explorado pelos estudos da linguagem. As cidades de Mariana e Ouro Preto, onde estamos localizados, parecem ocupar uma posição de destaque nesse cenário. Essas cidades mantêm os seus acervos documentais, literários, arquitetônicos e artísticos, como material disponível à pesquisa acadêmico-científica de estudiosos do mundo inteiro. Tais acervos encontram-se, em geral, nos arquivos físicos da região, como o Arquivo da Câmara Municipal de Mariana, que se encontra sob a guarda do ICHS-UFOP, os arquivos 
da "Casa Setecentista", o arquivo do Seminário Maior e o Arquivo da Cúria Metropolitana, em Mariana; no acervo de obras raras da Escola de Farmácia de Ouro Preto, no "Museu da Inconfidência" e nos diversos arquivos em que se distribuem a biblioteca e obras dos Inconfidentes. Além disso, no que diz respeito à Literatura, Música e Artes Plásticas, há que se ressaltar os acervos da casa de Alphonsus de Guimaraens e do poeta simbolista José Severiano de Rezende, em Mariana; de Bernardo Vasconcelos, Tomás Antônio Gonzaga e Cláudio Manoel da Costa; os acervos musicais, em parte reunidos no "Museu da Música", em Mariana, e o rico acervo artístico das igrejas, casarões, praças e monumentos das cidades da região. Esses acervos têm sido referência para alguns pesquisadores, principalmente nas áreas da História, da Arquitetura e, com menos vigor, da Literatura, cabendo aos estudos da linguagem uma potencialidade de pesquisa ainda latente.

Se a riqueza material da região é inegável, do ponto de vista de sua diversidade, qualidade e historicidade, podemos dizer a mesma coisa do seu patrimônio imaterial ou intangível, compreendido aqui como toda prática cultural realizada no interior das comunidades, por seus indivíduos, seja numa perspectiva do fazer individual, seja do fazer coletivo. Como exemplos dessas práticas, sobretudo em Mariana e Passagem de Mariana, distrito no qual intensificamos a nossa coleta de dados, podemos citar: (a) as manifestações musicais das Bandas de São Sebastião e de Santa Cecília, de Passagem de Mariana; (b) os rituais e festas religiosas, como a Festa de Nossa Senhora da Glória, em Passagem, e da Procissão das Almas, em Mariana; (c) as práticas terapêuticas, como as propiciadas pelas ervas de Dona Naná, em Passagem; (d) as artes cênicas e a ludicidade do Clube Osquindô, de Passagem; (e) o material discursivo ligado ao saber-fazer de mestres de ofício, como os ex-mineiros Antônio Bocarra, Antônio Pessoa e Firmino Assumção; (f) as benzedeiras, como Dona Chiquita, de Passagem, que recebe visitantes vindos de toda parte; e (g) as cozinheiras, como Dona Stela e suas deliciosas balas de cachaça mineira.

Para o presente texto, focalizaremos a análise de partes do Patrimônio Imaterial registrado em Passagem de Mariana, por meio de entrevistas com moradores antigos, guardiões da cultura e da memória local. Faremos, num primeiro momento, uma reflexão acerca da metodologia utilizada na coleta das entrevistas, a qual faz convergir procedimentos advindos das Ciências Sociais, para o trabalho com a pesquisa etnográfica, e procedimentos metodológicos da Análise do Discurso, para o tratamento do evento comunicativo que se dá a partir da interação entre entrevistador e entrevistado. Num segundo momento, buscaremos aproximar, na análise de um excerto de uma das entrevistas, alguns aspectos da relação 
entre memória, cognição e discurso, a partir de categorias oriundas de diferentes quadros teóricos, a exemplo de noções como "experienciação discursiva" (AUCHLIN, 2008), "performance e vocalidade" (ZUMTHOR, 1993), "memória cognitivo-discursiva" (PAVEAU, 2007), "espaço semiótico" (BRANDT, 2004), entre outras.

\section{Da entrevista à narração, do patrimônio ao corpus de pesquisa}

Para construir o banco de dados de narrativas orais, a pesquisa contou com algumas etapas norteadoras, quais sejam: 1) a etapa preparatória, que consistiu na definição de critérios de seleção dos entrevistados e do método de condução das entrevistas, bem como das estratégias de captação dos moradores e marcação das entrevistas; 2) a etapa de registro das entrevistas, marcada pela seleção de meios tecnológicos, adequados ao registro audiovisual das interações, e dos métodos de intervenção mais adequados a cada entrevistado, no que tange ao grau de regulação por parte do pesquisador; 3) a etapa de organização e arquivamento dos dados coletados, que passou pela elaboração de fichas de identificação e resumos das interações, a fim de identificar os principais temas abordados com cada entrevistado; 4) a etapa de transcrição e edição dos arquivos de áudio e vídeo, que está sendo atualmente desenvolvida; e, por fim, 5) a etapa de tratamento dos dados, a qual ocorrerá à medida que a análise for sendo desenvolvida, com a consequente apresentação dos resultados e o surgimento de novos pesquisadores interessados em estudar o material coletado.

\subsection{Etapa preparatória}

A etapa preparatória contou com uma parceria ${ }^{5}$ firmada entre o Grupo de Estudos sobre Memória e Discurso (GEDEM-UFOP) e a Associação Clube Osquindô, de Passagem de Mariana, por meio da qual pudemos estabelecer e agendar as primeiras entrevistas com os moradores. Selecionamos 16 informantes, de acordo com os seguintes critérios: ter idade acima de 60 anos; morar em Mariana há mais de 30 anos e ter um significativo grau de envolvimento com a vida política, social, religiosa e / ou profissional da região.

O Clube Osquindô nos auxiliou não só na seleção dos informantes e no agendamento das entrevistas como também nos forneceu temáticas, ou tópicosguias, mais próximos de cada um dos entrevistados. Optamos, então, pela utili- 
zação de tópicos-guias 6 , ou seja, "um lembrete para o entrevistador, um sinal de que há uma agenda a ser seguida, um meio de monitorar o andamento do tempo da entrevista (GASKELL, 2010, p. 64). O tópico-guia nos pareceu mais adequado do que a entrevista estruturada ou semiestruturada, por conferir maior dinamismo e fluidez à interação. Além disso, os procedimentos metodológicos empreendidos por nós levam em consideração a emergência da memória no processo enunciativo, como algo engendrado a partir do esforço de covalidação dos interlocutores que são, eles mesmos, coconstrutores das representações da memória postas no jogo interacional. Nesse sentido, o uso do tópico-guia enquanto norteador da interação nos propiciou uma regulação menos mecânica ("engessada") da troca comunicativa, embora focalizada, de acordo com o perfil de cada informante.

Essa caracterização prévia dos perfis dos entrevistados foi fundamental para gerar um campo de aproximação entre pessoas que não se conheciam previamente, o que acabou facilitando a emergência e o gerenciamento dos afetos presentes no jogo interacional.

\subsection{Etapa de execução}

Feito o agendamento com os entrevistados e mapeados os tópicos-guias, passamos à interação efetiva, a qual se deu na casa dos moradores e no local da casa indicado por eles. Em alguns casos, percebemos que a mudança de local dentro da casa, da sala para a cozinha, por exemplo, proporcionava maior descontração e fluidez para a entrevista, o que viabilizou o surgimento de narrações significativas no interior da interação.

Utilizamos um gravador digital de voz, para captação da parte verbal da entrevista; uma filmadora digital, para captação de imagens tanto dos entrevistados, quanto do local das entrevistas; e uma máquina fotográfica para o registro de imagens específicas (por exemplo: foto do entrevistado na janela da casa, de objetos antigos e de fotografias de família). Foram coletadas mais de 60 horas de entrevistas e cerca de 700 fotos foram tiradas na cidade e nas casas dos entrevistados.

Do ponto de vista do formato da interação, optamos pela mesclagem de procedimentos, advindos, sobretudo, das Ciências Sociais, os quais podem ser descritos como entrevista qualitativa, na forma como apresentam Gaskell (2010, p. 65), para quem a entrevista qualitativa busca mapear e compreender a vida dos respondentes e introduzir, a partir disso, esquemas interpretativos para compreender as narrativas dos atores em termos mais conceptuais e abstratos, muitas vezes 
em relação a outras observações. O objetivo desse tipo de entrevista é uma compreensão detalhada das crenças, atitudes, valores e motivações, em relação aos comportamentos das pessoas em contextos sociais específicos.

Baseamo-nos também, parcialmente, no método do Sociólogo Russo Flitz Schütze (1983), cujo foco é a entrevista narrativa, a qual convida o informante a narrar algum acontecimento importante de sua vida e do contexto social. A técnica recebe o nome de narrare e visa a obter narrativas da forma mais direta possível e com o mínimo de intervenção do entrevistador. O ambiente deve ser preparado para favorecer essa mínima intervenção do entrevistador. A ressalva que fazemos a esse método consiste no fato de ele se basear em uma técnica de extração de informações, tendo em vista um esquema autogerador que vai alimentando a narrações, sem que o entrevistador precise intervir. De fato, há entrevistados que narram a partir de um esquema autogerador e sem a intervenção do entrevistador, mas isso não se aplica a todos os perfis entrevistados por nós, por exemplo, uma vez que toda interação pressupõe graus de regulação por parte dos interlocutores, sob o risco de frustrar as expectativas construídas entre pesquisador e informante.

Sendo assim, buscamos intervir o mínimo possível, mas não hesitamos em nos colocar, quando o entrevistado nos solicitava esclarecimentos ou nos demandava perguntas e / ou a inserção de novos tópicos-guias. O grau de regulação da troca comunicativa, equalizado entre estratégias de proximia e distanciamento, variava de acordo com o perfil do entrevistado e com a representação que ele tinha do contrato de comunicação subjacente à interação. Para alguns, a constante presença do formato pergunta e resposta era imprescindível ao andamento da conversa; para outros, a simples inserção do tópico-guia já era suficiente para que a narração fluísse ininterruptamente.

Com relação à etapa de execução, destacamos também a importância da adequação da linguagem utilizada na interação, a fim de potencializar a aproximação afetiva com o entrevistado. Nesse sentido, evitamos formalismos desnecessários e linguagem excessivamente acadêmica.

\subsection{Etapa de organização e arquivamento}

$\mathrm{Na}$ etapa de organização e arquivamento do material registrado durante as interações, privilegiamos a criação de uma ficha de identificação das entrevistas, contendo dados dos entrevistados e da equipe envolvida, além de um resumo, contendo os principais tópicos-guias abordados. Os arquivos de áudio, as fotos e 
as imagens registradas foram organizados em pastas no Laboratório de Estudos do Discurso (LED - UFOP) e colocados à disposição de cada um dos informantes e à biblioteca mantida pelo Clube Osquindô, em Passagem de Mariana.

Como parte do banco de dados, as entrevistas registradas deverão estar disponíveis para a comunidade acadêmica em geral, a fim de que futuras pesquisas possam ser desenvolvidas no âmbito da graduação e da pós-graduação.

\subsection{Etapa de transcrição e edição de imagens}

Para a etapa de transcrição, ainda em desenvolvimento, adaptamos uma tabela ${ }^{7}$ de símbolos de transcrição, a fim de gerar parâmetros para todos os pesquisadores envolvidos em tal etapa. Procedemos também à edição de trechos e à inserção de legendas, para auxiliar a compreensão da fala dos informantes, de acordo com as demandas no interior das pesquisas em desenvolvimento.

Após essa breve descrição dos procedimentos metodológicos adotados para a coleta, registro, arquivamento e transcrição, passemos à reflexão acerca das entrevistas realizadas.

\section{A experienciação dialogada e o patrimônio imaterial marianense}

No Brasil, a ideia de que o patrimônio não se compõe apenas de edifícios e obras de arte erudita, remonta aos anos 1930 e se encontrava no projeto que o poeta modernista Mário de Andrade elaborou para o Serviço do Patrimônio Artístico Nacional, em 1936. Embora as tentativas de ampliação da noção de patrimônio tenham sido frustradas, Mário de Andrade, na prática, foi pioneiro no registro dos aspectos imateriais do patrimônio, deixando para a posteridade fotografias, gravações e filmes que realizou em suas famosas viagens ao Nordeste.

Foi somente em 2000, com a publicação do Decreto 3.551, no âmbito do Programa Nacional do Patrimônio Imaterial, que essa faceta do patrimônio cultural brasileiro passou a fazer parte de uma política pública de identificação, registro, inventário e divulgação. Contudo, com a valorização das tradições populares (festas, literatura, culinária, dança etc.), enquanto parte integrante do patrimônio cultural de uma comunidade, o registro dessas manifestações se tornou um desafio para os pesquisadores, em função do seu aspecto mutável e intangível, e variáveis, por exemplo, a periodicidade com que essas manifestações deveriam ser registradas passaram a complexificar o trabalho de pesquisadores em campo. 
Além disso, ações de salvaguarda não são suficientes como são para os exemplares do patrimônio material, uma vez que é preciso ainda implementar ações para tirar do anonimato essas manifestações, como é o caso das narrativas biográficas e dos sujeitos responsáveis por elas. De acordo com Maria Cecília Fonseca:

Para que essa função se cumpra, é necessário que a ação de "proteger" seja precedida pelas ações de "identificar" e "documentar" bases para a seleção do que deve ser protegido-, seguida pelas ações de "promover" e difundir", que viabilizam a reapropriação simbólica e, em alguns casos, econômica e funcional dos bens preservados (FONSECA, 2009, p. 67).

Nessa perspectiva, à medida que o produto das entrevistas passa a ser visto enquanto manifestação representativa do patrimônio imaterial de uma comunidade, a preparação de situações para que essas narrativas apareçam é fundamental e, para fins de preservação, foi preciso pensar uma interação que pudesse não só fazer emergir essas memórias como também nos possibilitasse um registro o mais adequado possível da performance dos informantes, no momento da interação.

Diante disso, defendemos a hipótese de que as noções de experienciação discursiva (AUCHLIN, 2008) e de performance (ZUMTHOR, 1993) são adequadas ao trabalho de produção, de registro e de análise de entrevistas, uma vez que consideram não só o material verbal produzido pelos informantes como também a presença corporal, a vocalidade, os afetos e a intersubjetividade imprescindível à compreensão do contexto em que essas interações emergem e dos sujeitos que as validam no aqui e agora da interação. Assim, estamos considerando também a presença dos pesquisadores que se envolveram nas entrevistas, conduzindo, regulando as trocas de turnos de fala, inserindo e retomando tópicos-guias e registrando toda a interação com aparelhos adequados à captação de imagem e som.

Para Auchlin (2008, p. 11), a experienciação discursiva "integra ou funde fluxos paralelos e coocorrentes de dados cognitivos abstratos e dados perceptivos sensório-motores, afetivos, intrassubjetivos, geralmente no quadro de uma interação com outra experiência discursiva". O que nos parece importante ressaltar é que a interação, vista sob essa perspectiva, faz convergir, numa dimensão intersubjetiva, uma experiência discursiva multimodal, em que a vivência corporal dos envolvidos entra em cena no jogo de validação do material verbal que vai sendo coconstruído, ou seja, das narrativas orais que emergem da troca comunicativa. A linguagem corporal, com seus gestos, expressões faciais e inflexões 
afetivas, entra no esquema de regulação com o que é dito, e isso possibilita a atualização de um patrimônio que, antes, estava no anonimato.

O conceito de performance, cunhado pelo medievalista Paul Zumthor, também nos parece bastante pertinente para se pensar as entrevistas realizadas com os moradores de Passagem de Mariana. De acordo com esse autor, a performance é

uma ação oral-auditiva complexa, pela qual uma mensagem é simultaneamente transmitida e percebida, aqui e agora [...] A transmissão de boca a ouvido opera o texto, mas é o todo da performance que constitui o locus emocional em que o texto vocalizado se materializa e donde procede e se mantém a totalidade das energias que constituem a obra viva (1993, p. 122).

A interação que se estabelece entre pesquisador e informante é estruturada a partir de um jogo performático, em que o texto ganha contornos não só da oralidade que o materializa como também de uma dimensão vocal, que vai além do som que emitimos ao falar. A vocalidade seria um fenômeno amplo que envolve os usos que fazemos da voz para alcançar determinados fins linguageiros. A voz é, nessa perspectiva, algo que "transforma, altera, transmuta o texto de que é objeto" (ZUMTHOR, 2005, p. 116).

$\mathrm{O}$ aspecto vocal das entrevistas realizadas não será explorado no presente texto, embora seja importante situarmos o leitor quanto à perspectiva que assumimos diante das narrativas orais, produzidas na interação entre pesquisador e informante, uma vez que a vocalidade, com a noção de experienciação e de performance, nos permite apreender a enunciação subjacente às entrevistas, do ponto de vista de sua complexidade e do que a permite existir enquanto mecanismo de produção das representações da memória em questão.

A vocalidade, nesse sentido, extrapola a noção de oralidade, pois se traduz pela relação que se estabelece entre o acento, a entonação do enunciado, sua duração, seu tom, sua medida e outros recursos performáticos, como os produzidos pela presença do corpo físico, a exemplo da postura, dos gestos, das expressões faciais e das inflexões afetivas que esse corpo coloca em cena.

A experienciação dialogada, vista como uma interação performática entre locutor e interlocutor, interroga o papel do pesquisador nessa troca comunicativa, que como um observador-participante, como postulam os que se interessam pela metodologia da pesquisa-ação, envolve-se subjetivamente, colocando também em cena o seu corpo vocal. 
A tradição dos estudos em Análise do Discurso quase sempre privilegiou a análise de textos, em que o analista se posiciona como um tiers-observador da prática de linguagem e suas condições situacionais, linguísticas e discursivas. Ele se posiciona de fora da troca comunicativa, colocando-se, vez ou outra, no lugar do destinatário projetado no texto, a fim de reconstruir a cena enunciativa, a partir da materialidade linguística (ou vice e versa).

A entrevista é, nesse caso específico, além de uma situação comunicativa, pautada na troca de turnos entre os interlocutores e estruturada pelo formato pergunta / resposta, parte da construção de um método investigativo para obtenção de corpus de pesquisa. Nessa perspectiva, o pesquisador se constitui enquanto um "EU", que se coloca no lugar de participante da troca comunicativa e, ao mesmo tempo, assume a posição de um pesquisador / analista, cuja motivação se encontra nos desafios impostos pela própria regulação e manutenção da troca e, ao mesmo tempo, nas dificuldades inerentes à autogestão do método escolhido para a obtenção de representações da memória.

$\mathrm{O}$ esquema a seguir nos permite visualizar o lugar ocupado pelo analista-entrevistador na interação com o informante entrevistado.

FIGURA 1

A entrevista como método investigativo de constituição de corpus

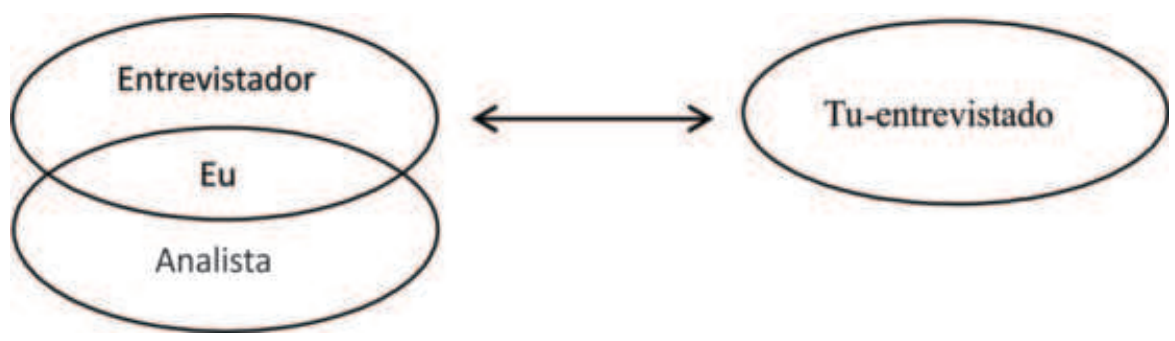

\section{Do nicho biocultural aos lugares de memória}

Buscamos desenvolver aqui uma abordagem que estabeleça relações integradas entre cognição, memória e linguagem, do ponto de vista da experienciação discursiva. Assumimos, como ponto de partida, o princípio da 'mente corporificada', segundo o qual nosso pensamento e nossas ações são 
cognitivamente estruturados a partir de nossas capacidades sensório-perceptuais, ou ainda, das condições de interação organismo / ambiente. A propósito, vejamos como M. Johnson (2007) traduz o fundamento dessa concepção sobre o conhecimento:

para termos sentido humano, nós necessitamos de um cérebro humano, operando em um corpo humano vivo interagindo continuamente com um ambiente humano que é, ao mesmo tempo, físico, social, e cultural. Subtrai-se uma destas três dimensões, e esvai-se a possibilidade de sentido: sem cérebro, nada de sentido; sem corpo, nada de sentido; sem ambiente (nicho), nada de sentido (JOHNSON, 2007, p. 155). ${ }^{8}$

Isso nos remete a uma problematização sobre a noção de memória e de linguagem não só do ponto de vista cognitivo e discursivo mas também do ponto de vista ecológico. Nesse sentido, nossa concepção converge com o que Sinha (2009, p. 306) chama de teoria biocultural da linguagem, a qual, segundo ele, "instaura, literalmente, a vida na linguagem, por muito tempo reduzida a estruturas e operações formais". Destacamos aqui a noção de nicho biocultural, formulada pelo autor, em termos de repertórios ecológicos evolutivamente desenvolvidos, os quais são constitutivos do modo específico de ser / viver / agir de certas espécies animais, entre elas, o homem. Nas palavras de Sinha:

Os ecologistas enfatizam que as espécies configuram (e são configuradas por) seus nichos. Os comportamentos dos organismos efetuam transformações do ambiente ao qual devem se adaptar. Em muitos casos, ocorrerá um processo de realimentações positivas no qual organismo e ambiente estejam em relações complementares, cada um configurando o outro (SINHA, 2009, p.293). ${ }^{9}$

Segundo esse modelo, a integração de aspectos ecológicos na teoria evolucionista, especificamente a existência de nichos animais artefatuais, mina a distinção entre genótipo e fenótipo, "replicador" e "veículo". É melhor dizer que, mesmo considerando que a unidade da seleção darwiniana permanece no gene (alelo), o "replicador" inclui não só o nicho artefatual mas também o repertório comportamental do nicho adaptativo do animal, com suas affordances, possibilidades de interação, no sentido da psicologia ecológica de Gibson (1986). Isso favorece as propriedades emergentes da sociedade e dos organismos. 
Nessa perspectiva, a Linguagem é concebida como "um nicho artefatual, e a capacidade para desenvolvê-la envolve a evolução e a replicação de um 'complexo biocultural' fenogenotípico" (SINHA, p. 296). Como tal, a linguagem é situada e integrada dinamicamente à semiose desse complexo biocultural, de modo que:

Esse complexo biocultural nós podemos, para utilizar a terminologia do semioticista russo Yuri Lotman (1990), designar como a semiosfera humana, o ambiente significativo, construído, que é reproduzido através das gerações humanas do mesmo modo que acontece com o próprio organismo humano. É crucial apreciar, nesse contexto, que a semiosfera, como outros nichos artefatuais animais, não é meramente um constituinte do que é reproduzido, mas é também um mecanismo fundamental no processo de reprodução e transmissão. Por causa de sua pré-eminência na mediação entre a reprodução cultural e os processos cognitivos individuais, a linguagem é o primeiro e mais distintivo constituinte da semiosfera humana (op. cit, p.296-7). ${ }^{10}$

Assumimos, pois, que a linguagem, de um modo geral, e as manifestações culturais, como o patrimônio imaterial, que constitui nosso objeto de pesquisa, são constitutivos do nosso nicho biocultural, e que a memória tem um fundamento ecológico, embora deva ser parametrizada socioculturalmente e, sobretudo, discursivamente, fazendo parte da rede integrada da semiosfera humana.

Uma vez que estamos assumindo uma concepção integrada entre cognição, memória e linguagem, em função das práticas discursivas que engendram os acervos culturais, situamos o aparelho formal da enunciação (Benveniste) e o dialogismo (Bakhtin / Volochinov) no cerne da semiosfera humana, como base do sistema biocultural que se traduz pelos acervos, a exemplo do corpus constituído pelas entrevistas com os moradores de Passagem de Mariana. Defendemos a hipótese de que o dispositivo enunciativo, ao instituir as categorias de pessoa e tempo / espaço, engendra as operações dialógicas necessárias para a constituição da semiosfera humana, enquanto rede integrada de formas de vida, de construção de relações intersubjetivas e de representação da memória.

Considerando-se o princípio da corporificação (embodiment) da mente, a experiência corporal constitui, pois, a base da nossa capacidade de memória. A propósito, destacamos a formulação de Ricoeur (2007), que, ao abordar os 'lugares de memória', afirma que 
o corpo constitui o lugar primordial, o aqui em relação ao qual todos os outros lugares são lá. Nesse aspecto, a simetria entre espacialidade e temporalidade é completa: 'aqui' e 'agora' ocupam a mesma posição entre os dêiticos que pontuam a nossa linguagem (RICOEUR, 2007, p. 59).

Essa dimensão do corpo como lugar primordial de memória e, portanto, de significação, é de fundamental importância para nossa abordagem da experienciação dialogada, convergindo com nossa hipótese de que o dispositivo enunciativo, em seu funcionamento dialógico, está na base da semiosfera humana, que, no nosso caso específico, se faz representar pela entrevista, como prática discursiva que emerge a partir da copresença experiencial dos interlocutores, pesquisador-entrevistador e morador-entrevistado. Nesse sentido, é também bastante significativo que Ricoeur $(2007$, p. 57) ressalte que "a transição da memória corporal para a memória dos lugares é assegurada por atos tão importantes como orientar-se, deslocar-se, e, acima de tudo, habitar". Entre os processos de significação do espaço, orientados em função do corpo / organismo em função de sua integração ao ambiente, o autor destaca o de "habitar" como lugar de memória ${ }^{11}$ privilegiado do ponto de vista da experiência do sujeito. O que nos interessa pontuar nesse momento é que as entrevistas foram realizadas justamente nas casas dos moradores, ambiente / nicho por excelência ao qual os entrevistados se sentiam mais integrados experiencialmente, do ponto de vista da sua constituição identitária e do sentimento de pertença à comunidade, o que, a princípio, configurava um espaço mais propício à emergência das narrativas e, por conseguinte, das representações da memória.

Essa concepção converge com a proposição de uma memória cognitivodiscursiva $^{12}$ (PAVEAU, 2007), que nos parece a mais pertinente para lidar com a complexidade de nosso objeto. Tal formulação reconhece o princípio da 'mente corporificada', mas avança na direção da cognição social, enquanto fenômeno emergente em condições históricas e culturais, resultante de ações discursivas de sujeitos socialmente relacionados. E mais, essa hipótese assume o caráter dinâmico e distribuído da cognição, no sentido de ser processada não só de maneira multimodal (sensório-perceptual) pelos sujeitos mas também de estar inscrita e de circular por meio de uma gama extremamente complexa e variável daquilo que aqui chamamos de artefatos de nosso nicho biocultural (entrevistas, documentos de acervos, meios de comunicação em geral etc.). Paveau (2007) apresenta sua definição de cognição distribuída como sendo: 
Um processo de transmissão sincrônica e diacrônica de quadros prédiscursivos coletivos, esses últimos (conhecimentos enciclopédicos, crenças, emoções, percepções) sendo distribuídos de maneira colaborativa entre os agentes humanos e não humanos graças a organizadores psíquicos internos e externos (PAVEAU, 2007, p. 243).

Nesses termos, a autora se propõe a ultrapassar uma visão estática e / ou estocástica da memória, para concebê-la como um verdadeiro operador prédiscursivo e discursivo. Assim, a autora destaca três dimensões de sua noção de memória que justificam a articulação entre o cognitivo e o discursivo. A primeira delas relaciona-se à natureza ativa da memória enquanto processo (re)construtivo, ou ainda, de (re)categorização do mundo e, por conseguinte, de recriação do vivido, no sentido de 'reelaborar' discursivamente o passado em função do presente enunciativo. A segunda dimensão refere-se às ligações memoriais, inscritas no desenrolar da história, as quais, segundo a autora, são fundamentais para a produção dos discursos e distribuição dos saberes e crenças, de um ponto de vista tanto sincrônico quanto diacrônico. A terceira e última dimensão diz respeito ao papel fundamental dos afetos e emoções na constituição e no funcionamento da memória cognitivo-discursiva, o que é pertinente com uma concepção experiencial das interações e da produção de sentido naquilo que chamamos de rede complexa da semiosfera humana.

\section{Interação e espaço semiótico}

O modelo da semiótica cognitiva,$^{13}$ na versão formulada por Brandt (2004) e adaptada por Oakley (2009), apresenta uma forma operacional de trabalhar com um recorte significativo dessa rede complexa da semiosfera humana, ao propor uma arquitetura de espaços projetados pelos sujeitos em suas interações. Nessa perspectiva, a noção de espaço se traduz aqui pela projeção de esquemas / cenários cognitivos construídos pelos sujeitos durante suas interações. Portanto, "a semiose (a situação em que enunciados ou outras trocas de sinais ocorrem) é a base para a construção de espaços" (BRANDT; BRANDT, 2005, p. 19). A noção de espaço base semiótico é, assim, definida:

Um espaço (base) semiótico é um espaço mental em que o [sujeito] cognoscente representa a situação atual de conhecer. Ou é uma cena de comunicação, envolvendo as pessoas que participam na constru- 
ção de significado compartilhado através da rede semântica considerada, ou uma cena de reflexão envolvendo o sujeito "que reflete" e a situação em que a reflexãotem lugar, tal como representada pelo sujeito. Assim, é assumido como sendo o caso, fenomenologicamente, que quando as pessoas se comunicam, eles representam a situação de comunicação, e essa representação compartilhada é um pré-requisito para a construção de sentido ${ }^{14}$ (BRANDT; BRANDT, 2005, p. 20).

Na versão apresentada por Brandt (2004) e adaptada por Oakley (2009), a arquitetura dos espaços é composta: (i) pelo espaço base semiótico (o qual é desdobrado em três esferas: a da semiose propriamente dita, enquanto instância de realização de atos de linguagem pelos interlocutores; a da situação de comunicação em que se encontram os participantes da interação; e a do mundo fenomenológico mais amplo, acessível à nossa experiência vivida); (ii) pelos espaços de entrada, chamados de espaço de apresentação (instância textual) e de referência (instância objeto); (iii) pelo espaço virtual, projetado a partir da seleção de elementos dos frames dos dois últimos espaços; e (iv) espaço de relevância, o qual orienta o sentido emergente do espaço virtual. O diagrama abaixo representa essa arquitetura semiótica proposta pelos autores em questão:

\section{FIGURA 2}

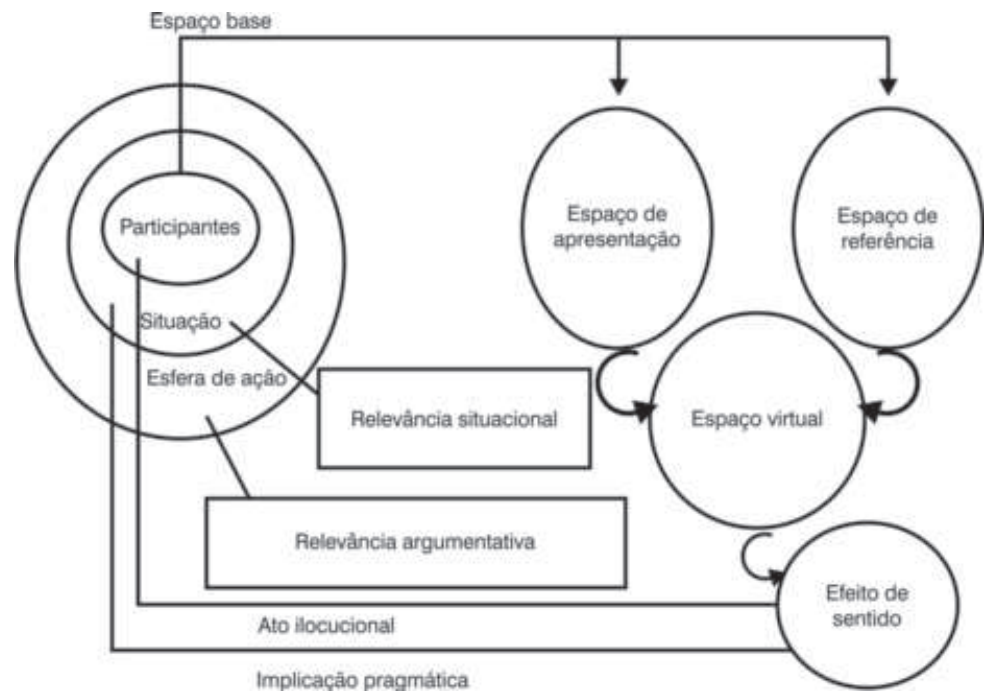


Projetando os elementos da nossa pesquisa no esquema semiótico acima, podemos começar descrevendo a estruturação daquilo que representa a configuração do seu espaço base semiótico, delineado a partir da relação entre os participantes da interação, que se traduzem pelo pesquisador / entrevistador e pelos moradores / entrevistados. Essa interação se estabelece primeiramente numa esfera social de ação, estabelecida sob a forma de uma visita previamente agendada pelo grupo Osquindô, conforme já relatado nas etapas de realização da pesquisa. Essa visita é atualizada sob a forma da situação de comunicação 'entrevista', cujos atos de linguagem que colocam em funcionamento a experienciação dialogada são, prioritariamente, as perguntas, que introduzem os tópicosguias, e as repostas, a partir das quais emergem as narrações com suas respectivas representações da memória. Nesse sentido, a relevância argumentativa e situacional que caracteriza o espaço de relevância da nossa pesquisa é exatamente o fato de que a visita tem a função estratégica de registrar o patrimônio imaterial da região e a entrevista favorece a emergência desse patrimônio sob a forma da experienciação dialogada. Buscamos representar esse processo no diagrama abaixo:

\section{FIGURA 3}

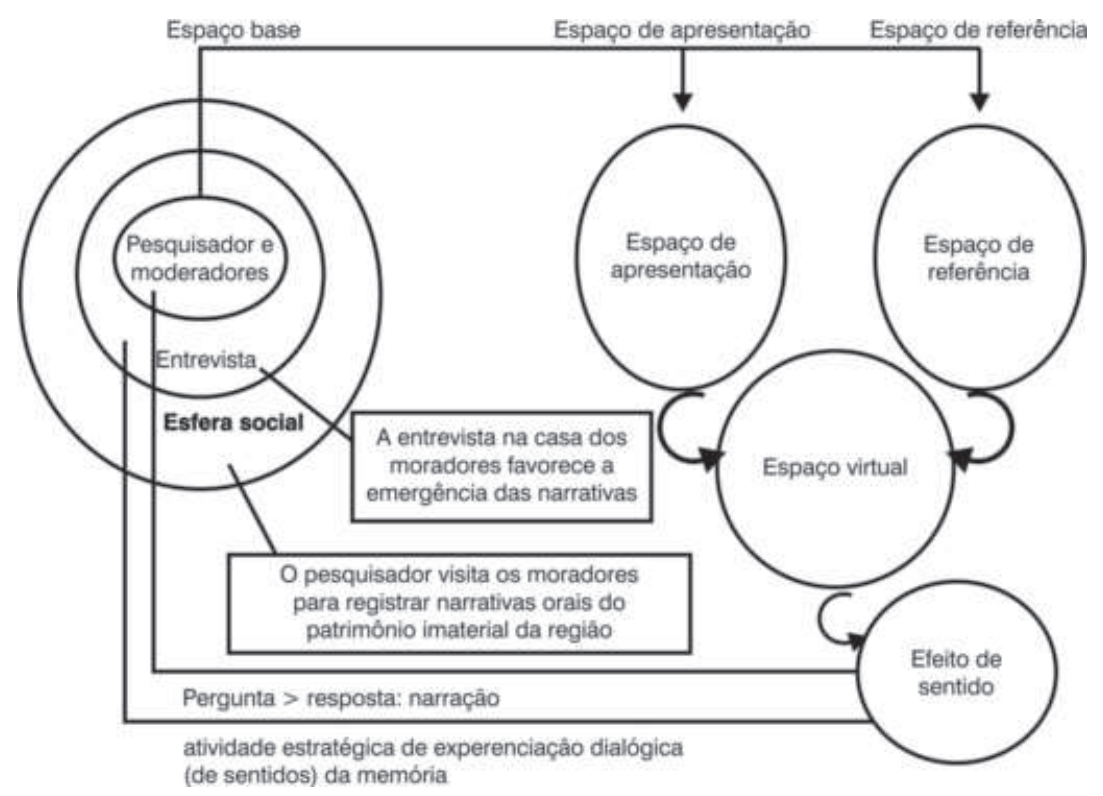




\subsection{Esboço de análise de um tópico-guia de uma entrevista}

Elaboramos, na sequência, uma pequena análise de um breve fragmento de uma das entrevistas realizadas, com vistas a ilustrar o desenvolvimento de um tópico-guia, em termos de alguns aspectos da experienciação discursiva, com ênfase nos processos de enunciação e referenciação. Fazemos, aqui, uma ressalva relativa ao fato de que, neste artigo, não foi possível apresentar uma análise das filmagens, em termos de um tratamento da dimensão prosódica e / ou mimo-gestual das interações, a qual ultrapassaria os objetivos programáticos deste texto. $\mathrm{O}$ estudo dessa dimensão, fundamental para nossa abordagem da experienciação discursiva, demanda a utilização de instrumentos e procedimentos metodológicos que estão sendo trabalhados, com vistas a elaboração de futuras análises, que serão objeto de outras publicações. Nesse sentido, o que apresentamos agora é apenas um esboço de análise inicial do seguinte trecho extraído do material coletado:

Exemplo 1:Trecho da entrevista realizada com as irmãs N1 e N2, em 27/04/2012, em Passagem de Mariana

Trecho 4: 0' a 2'9"' (Assombrações)

P1 Me fale um pouquinho das lendas aqui de Passagem

N1 hi::lendas

$\mathrm{P} 1$ as assombrações

$\mathrm{N} 2$ ah!

N1 eu não tenho medo de assombração por isso que eu não acredito

P1 a senhora não acredita não?

N1 eu nunca vi

N2 eu também nunca vi não mas não quero ver também não

N1 ( )mas não tenho medo também não. Eu não tenho não mas que FALAram que ANTIGAMENTE.. da minha vó bisavó falava que tinha assombração mas eu nunca vi

$\mathrm{N} 2$ aqui na nossa rua mesmo tinha

$\mathrm{N} 1$ eu não tenho medo

P1 o que que tinha?

N2 aparecia uns trupéu aí diferente né!?

P1 o quê?

N1, N2 ehn?

N2 uns trupéu

N1 é uma zoeira que aparecia aqui 
P1 ah! Um trupéu é uma zoeira

N2 é

P1 um barulho assim estranho

N1 barulho

N2 teve uma vez que...

N1 o cabrito saiu correndo

[

N2 dormia muito cabrito aqui nana porta né!?

N1 igual um leão pra rua afora

N2 os cabrito quando viram o negócio saíram tudo calado

N1 correndo

N2 correndo

N1 eu nunca vi..nunca vi mesmo ( )

N2 teve uma vez que meu pai ainda era vivo..ele trabalhava na companhia..ele ia chegar

N1 de manhã cedo

N2 ele trabalhava de manhã..ele tinha entrado dez horas da noite e chegar só no outro dia de manhã né!? Nós acordamos com minha mãe "levanta que parece que tem ladrão querendo entrar aqui em casa"..aí levantou todo mundo e quando nós levantamos tava aquela zoeirada mesmo sabe aquela zoeira esquisita né..aí nós acendemos as luzes da casa toda, porque se for ladrão eu falo tem gente aí e vai embora né..aí quando foi mais tarde né Mundica..aí cessô..minha mãe falou "sabe duma coisa, vamos rezar o terço".. aí nós trepamo tudo na cama com ela

N1 Therezinha trepou na cama com o sapato na mão "ladrão vier aqui, vou jogar um sapato na cara dele"..ah tá! Dá sapato vai matar o ladrão mesmo - risos-

N2 aí né rezamos o terço..quando tava terminando o terço passou um trupéu. assim parecia que tava com um tamanquinho assim - trec, trec-

N1 eu queria abrir a janela a mamãe falava "não vai abrir não"

N2 mamãe falava assim "tá na rua deixa na rua"

N1

[

P1 a senhora não tinha medo nenhum..queria logo abrir a janela

N1 eu queria abrir a janela pra mim ver o que que era ué

A sequência acima é um trecho de entrevista realizada com duas irmãs (N1 e N2) que moram juntas no distrito de Passagem de Mariana. A sequência tem início com um demanda de informação por parte do pesquisador (P1) acerca 
de um tópico-guia, a saber, as lendas de Mariana. Curiosamente, a resposta de N1 - "Hi:: lendas"- denota uma hesitação e aparente desconhecimento do significado, ou ainda, um esforço para ativar na memória um frame relativo ao tópico 'lenda'. Ao perceber essa hesitação e o custo cognitivo expresso por ela, o pesquisador reformula imediatamente o tópico-guia, por meio da expressão "as assombrações", com a intenção de tornar mais clara a demanda de informação e fazer fluir a interação. Notamos que a reformulação foi bem-sucedida, a exemplo da interjeição "ah", de N1, indicativa de compreensão da demanda, seguida do comentário de N1 "eu não tenho medo de assombração, por isso que eu não acredito". A partir daí, a interação se desenrola numa sequência de intervenções, motivadas pela pergunta do pesquisador: "A senhora não acredita não?" , as quais se caracterizam pela contradição e / ou contraposição de pontos de vista de N1 e N2 sobre a existência ou não de assombrações:

N1 eu nunca vi

N2 eu também nunca vi não mas não quero ver também não

N1 ( )mas não tenho medo também não. Eu não tenho não mas que FALAram que ANTIGAMENTE.. da minha vó bisavó falava que tinha assombração mas eu nunca vi

N2 aqui na nossa rua mesmo tinha

N1 eu não tenho medo

Na sequência acima, enquanto N1 diz nunca ter visto e não sentir medo, $\mathrm{N} 2$ afirma que nunca viu, mas que também não quer ver, o que expressa um certo medo. Sobretudo, quando N1 utiliza o discurso relatado para dizer que as gerações passadas falavam em 'assombração', reiterando que nunca viu, N2 encadeia uma asserção que contradiz N1, dizendo "aqui na nossa rua mesmo tinha", em que a elipse do referente permite inferir o implícito "tinha assombração".

Nesse momento da interação, após N1 enunciar, mais uma vez, que 'não tem medo', orientando seu enunciado argumentativamente em contraposição a N2, P1 interfere na troca, enunciando uma pergunta: "o que que tinha?", cujas respostas e demais enunciados a ela relacionados são especialmente significativos para o processo de referenciação e para a experienciação dialogada. A resposta imediata de N2 -“aparecia uns trupéu aí diferente né!?” - instaura um novo referente, dessa vez não compreendido por P1, que pergunta novamente: "o quê?", sendo respondido reiteradamente por N2, "uns trupéu", e esclarecido descritivamente por N1, "é uma zoeira que aparecia aqui". Em seguida, P2 produz uma definição, sob a forma de uma demanda de confirmação: "um trupéu é uma zoeira", 
a qual é satisfeita por N2: "é”. P1 reformula a demanda de confirmação, assegurando-se da compreensão e da regulação da interação, "um barulho assim estranho", sendo atendido por N1, que confirma: "barulho".

A recategorização operada sobre o referente 'assombração', que passa a significar "trupéu", o qual, por sua vez, é definido como "zoeira", reorienta a experienciação discursiva do fenômeno, que antes era focalizado exclusivamente em termos da sua percepção visual, e passa agora a ser focado também do ponto de vista de sua percepção auditiva. Em outras palavras, o fenômeno da "assombração / trupéu / zoeira” é algo que nunca foi visto por N1 nem N2, mas que já foi ouvido de alguma forma.

Isso confere verossimilhança à narração, sendo coerente com o episódio dos "cabritos que dormiam na porta da casa e saíram correndo quando viram o negócio". As experiências narradas durante a interação são orientadas sempre em função de coordenadas dêiticas que situam N1 e N2 no espaço interior da casa, ao passo que o fenômeno da "assombração / trupéu / zoeira" é sempre localizado no espaço exterior da casa, o que explica, de certo modo, o fato de tal fenômeno poder ter sido visto pelos cabritos, mas não pelas moradoras, o que não impede que ele tenha sido ouvido por elas.

$\mathrm{O}$ ápice do desenvolvimento desse tópico-guia nessa entrevista ocorre com o encaixamento de uma narração de uma experiência vivida por N1 e N2, envolvendo ingredientes de uma 'história de assombração', como mistério e medo. Ela é narrada por N2, que diz: "teve uma vez que meu pai ainda era vivo.. ele trabalhava na companhia.. ele ia chegar", e corroborada por N1, que completa: "de manhã cedo". A ausência do pai foi o primeiro elemento rememorado pelas irmãs, aparecendo como índice de insegurança, pois elas ficavam vulneráveis apenas em companhia da mãe. É justamente a mãe, cuja fala é reportada na narração, que acorda as filhas, suspeitando da presença de ladrão na casa - "levanta que parece que tem ladrão querendo entrar aqui em casa". Instaura-se um ambiente de suspense e, ao mesmo tempo, de verossimilhança, o que é reforçado pela enunciado seguinte de N2: "aí levantou todo mundo e quando nós levantamos tava aquela zoeirada mesmo, sabe aquela zoeira esquisita né". Mãe e filhas sobem na cama para rezar o terço e, depois que a tensão é amenizada, o fenômeno volta a ser ouvido, mas agora experienciado não como uma "zoeira", mas como um "trupéu suave", tal como relata N2: "aí né rezamos o terço.. quando tava terminando o terço passou um trupéu.. assim parecia que tava com um tamanquinho assim trec, trec-". Curiosamente, N1 reitera sua falta de medo e sua vontade de abrir a janela para ver o que se passava na rua, sendo impedida pela mãe. 
Cabe destacar que, entre os processos de referenciação, a presença metafórica do 'tamanquinho' e da onomatopeia 'trec-trec' reforçam a relevância da dimensão 'corporificada', sensório-motora, da produção dos sentidos da memória, experienciados discursivamente por meio da interação propiciada pela entrevista. Podemos agora apresentar novamente o diagrama do 'espaço semiótico', preenchido integralmente:

\section{FIGURA 4}

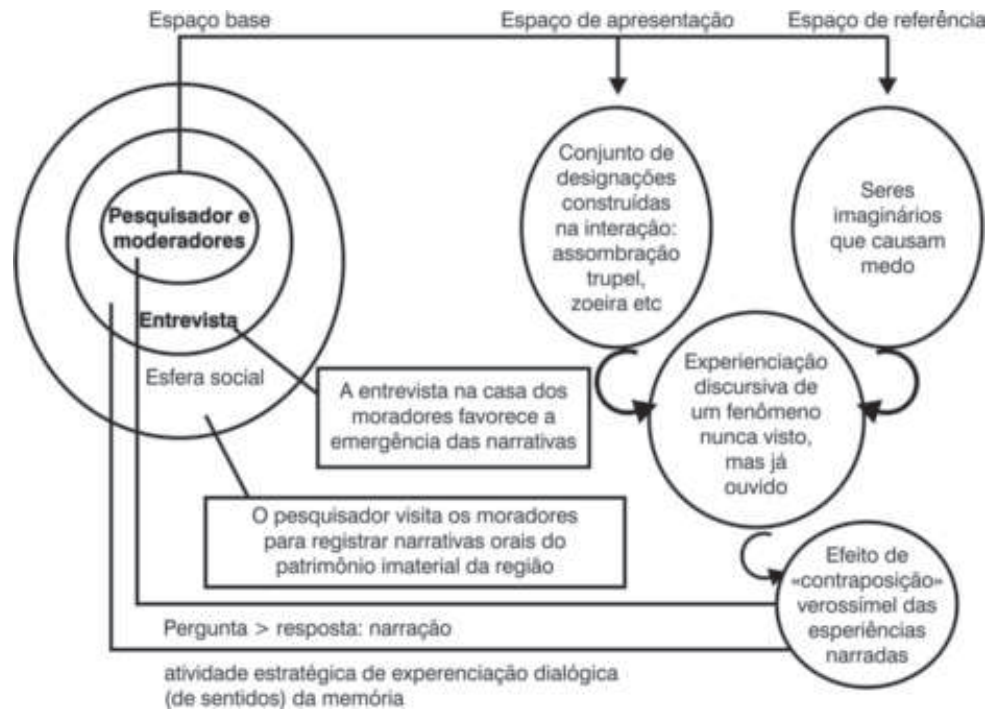

\section{Considerações finais}

O percurso teórico-metodológico realizado neste trabalho, que culminou no esboço de análise aqui apresentado, possibilitou-nos perceber que a experienciação dialogada emerge como uma prática discursiva multimodal, que, segundo nossa hipótese, parece ser mais bem compreendida no âmbito das relações integradas entre linguagem, cognição e memória.

A noção de nicho biocultural (SINHA, 2009) permitiu situar a linguagem e as operações de espacialização num complexo semiótico fundamental para 
se compreender a produção das entrevistas a partir da presença corporal dos participantes na troca comunicativa. A integração corpo / organismo e espaço / nicho funciona como um processo de filtragem de sentidos e, nas entrevistas, definiram a elaboração narrativa das quais emergiram as representações da memória dos entrevistados.

Nesse sentido, as entrevistas, representativas do patrimônio imaterial marianense, foram analisadas tendo em vista as operações representadas pela arquitetura de espaços semióticos (BRANDT, 2004; OAKLEY, 2009), engendrada em torno de tópicos-guias, os quais conduziram a interação entre os participantes, permitindo que eles fossem (re)construindo suas memórias em torno do evento comunicativo, socialmente situado.

Nosso artigo teve o objetivo programático de apresentar as diretrizes gerais de nossa pesquisa sobre o patrimônio imaterial. Há muito ainda por ser feito tanto do ponto de vista do aprofundamento da discussão teórica, que a complexidade do tema requer, quanto da perspectiva do aprimoramento metodológico, que o tratamento dos dados exige, em função de sua riqueza e multiplicidade de possibilidades de análise.

\section{Notas}

${ }^{1}$ Bolsista do Programa Nacional de Pós-doutorado da CAPES (PNPD) - UFOP.

${ }^{2}$ A referida pesquisa está sendo desenvolvida pela bolsista do Programa Nacional de Pósdoutorado da CAPES, Simone de Paula dos Santos Mendes.

${ }^{3}$ Projeto desenvolvido por Paulo Henrique A. Mendes no Programa de Pós-Graduação em Letras: Estudos da Linguagem, na UFOP.

${ }^{4}$ Ambos os projetos se inserem em um projeto maior, intitulado "Discursos sociais, estratégias discursivas e representações da memória: explorando acervos da Região dos Inconfidentes", coordenado pelo Professor Doutor William Augusto Menezes (UFOP), no âmbito das pesquisas desenvolvidas pelo Grupo de Estudos sobre Discurso e Memória (GEDEM-UFOP).As informações presentes neste artigo, acerca do projeto "Discursos sociais, estratégias discursivas e representações da memória: explorando acervos da Região dos Inconfidentes", processo número 475217/2009-8, foram extraídas do relatório técnico de pesquisa enviado ao CNPq, relativo ao período entre 29/11/2009 e 21/11/2011. ${ }^{5}$ Do ponto de vista da parceria firmada, o registro dessas narrativas orais objetivou também auxiliar a Associação Clube Osquindô na realização do projeto "Série Nossas Histórias - Coleção Mariana", em fase de preparação. Em síntese, o projeto "Série Nossas 
Histórias" viabilizará a coleta de algumas histórias e causos de Passagem de Mariana, os quais deverão ser gravados pela equipe do GEDEM e, em seguida, passarão por uma seleção para que seis histórias e causos escolhidos recebam tratamento dramatúrgico e componham um $\mathrm{CD}$ de áudio-histórias, que terá tiragem de 2.000 cópias e será desenvolvido por uma equipe formada, exclusivamente, por profissionais da região.

${ }^{6}$ Exemplos de tópicos-guias utilizados nas entrevistas: Mina de ouro, lendas, histórias de assombração, Festa de Nossa Senhora da Glória, Banda de São Sebastião e Santa Cecília etc. ${ }^{7}$ A tabela de símbolos (ANEXO A) foi adaptada de: PIRES, Maria Sueli de Oliveira. Estratégias discursivas na adolescência. São Paulo: Arte \& Ciência/UNIP, 1997 e de FÁVERO et. al. Oralidade e escrita - perspectivas para o ensino de língua materna. $8^{\mathrm{a}}$. ed. Cortez: São Paulo, 2005, a fim de atender aos propósitos da presente pesquisa.

8 "In order to have human meaning, you need a human brain, operating in a living human body, continually interacting with a human environment that is atonce physical, social, and cultural. Take away any one of these three dimensions, and you lose the possibility of meaning: no brain, no meaning; no body, no meaning; no environment, no meaning" (JOHNSON, 2007, p. 155. Tradução nossa).

9 "Ecologists emphasize that species shape, as well as being shaped by, their niches. Organismic behaviours may eventuate in significant transformations of the very environment to which the organism must adapt. In many cases, a process of positive feedback will occur in which organism and environment are in a complementary relationship, each shaping the other" (SINHA, 2009, p. 293. Tradução nossa).

10 "This complex biocultural we can, to use the terminology of the Russian semiotician Yuri Lotman (e.g. Lotman, 1990), designate as the human semiosphere, the construed, meaningful environment that is reproduced down the human generations along with the human organism itself. It is crucial to appreciate, in this context, that the semiosphere, like other animal artefactual niches, is not merely a constituent to what is reproduced, but is also the fundamental mechanism in the process of reproduction and transmission. Because of its pre-eminence in mediating both cultural reproduction and individual cognitive processes, language is the primary and most distinctive constituent of the human semiosphere" (SINHA, 2009, p. 296-7. Tradução nossa).

${ }^{11}$ É preciso fazer uma ressalva relativa ao fato de que sabemos que a questão dos 'lugares de memória' não se limita à menção que aqui fazemos a um pequeno excerto da obra de Ricouer. Essa problemática é amplamente desenvolvida na obra desse autor, bem como na de outros, a exemplo de P. Nora, mas não dispomos de espaço suficiente para tratá-la com o devido cuidado neste artigo, até porque não constitui um de nossos objetivos programáticos.

${ }^{12}$ Não desconhecemos a noção de memória discursiva (COURTINE, 1981) como conceito importante entre os modelos de análise do discurso, o qual remete à historicidade da materialidade do discurso, do ponto de vista de sua inscrição constitutiva nas práticas socioculturais. Por razões referentes às condições espaço-temporais para a conclusão de nosso artigo, optamos por não desenvolver uma problematização sobre tal noção, uma vez que não recorremos a ela para a realização do esboço de análise aqui apresentado. 
${ }^{13}$ A semiótica cognitiva (BRANDT, 2004) dialoga com a teoria dos espaços mentais, especialmente com as versões mais recentes do modelo da integração conceitual (FAUCONNIER; TURNER, 2002), mas apresenta uma abordagem cognitiva cuja ancoragem discursiva é mais consistente do ponto de vista de uma consideração mais efetiva da situação de enunciação.

14"A semiotic (base) space is a mental space in which the cognizer represents the present situation of cognizing. It is either a scene of communication, involving the persons participating in shared meaning construction through the semantic network considered, or a scene of reflection involving the reflecting subject and the situation in which the reflection takes place, as represented by the subject. It is thus assumed to be the case, phenomenologically, that when people communicate, they represent the situation of communication, and this shared representation is a prerequisite for meaning construction" (BRANDT; BRANDT, 2005, p. 20. Tradução nossa).

\section{Referências}

AUCHLIN, A. Sobre a integração experiencial do discurso. In: MARI, H., MENDES, P.H.A. (Orgs.) Revista Scripta. v. 12, n. 22. Belo Horizonte: PUC Minas, 2008.

BRANDT, P. A. Spaces, Domains, and meaning - essays in cognitive semiotics. Germany: Peter Lang, 2004.

BRANDT, L; BRANDT, P. A. Making sense of a Blend. In. MENDOZA IBÁÑEZ, R. (Ed.) Annual Review of Cognitive Linguistics. Amsterdam: John Benjamins, 2005. v.3. COURTINE, Jean-J. Quelques problèmes théoriques et métodologiques en analyse du discours. À propos du discours communiste adressé aux chrétiens. Langages 62, Analyse du discours politique. Paris: Larousse, 1981. p. 9-128

FÁVERO, L. L.; ANDRADE, M. L. C. V. O.; AQUINO, Z. G. O. Oralidade e escrita perspectivas para o ensino de língua materna. $8^{\mathrm{a}}$. ed. Cortez: São Paulo, 2005.

FONSECA, Maria Cecília Londres Fonseca. Para além da pedra e cal: por uma concepção ampla de patrimônio cultural. In: ABREU, Regina; CHAGAS, Mário (Org.). Memória e Patrimônio - ensaios contemporâneos. $2^{\mathrm{a}}$ ed.. Rio de Janeiro: Lamparina, 2009. p.59-79. GASKELL, George. Entrevistas individuais e grupais. In: BAUER, Martin W.; GASKELL, George. Pesquisa qualitativa com texto, imagem e som - um manual prático. $8^{\mathrm{a}}$ ed. Petrópolis / RJ: Vozes, 2010.

GIBSON, James J. The ecological approach to visual perception. London: Lawrence Erlbaum Associates Publishers, 1986.

JOHNSON, M. The meaning of the body - A esthetics of human understanding. Chicago: The University of Chicago Press, 2007.

OAKLEY, T. From attention to meaning - explorations in semiotics, linguistics and rhetoric. 
Bern: Peter Lang, 2009.

PAVEAU, M-A. Reencontrar a memória - percurso epistemológico e histórico. In: (Org.) FERREIRA, M.C., INDURSKY, F. Análise do discurso no Brasil: mapeando conceitos, contrapondo limites. São Carlos: Clara Luz, 2007.

PIRES, Maria Sueli de Oliveira. Estratégias discursivas na adolescência. São Paulo: Arte \& Ciência/UNIP, 1997.

RICOEUR, P. A memória, a história, o esquecimento. Campinas: Ed. Unicamp, 2007.

SCHÜTZE, F. Narrative. Repraesentation Kollektiver Schicksals betroffenheit. In: E. LAEMMERT (Org.). Erzaehlforschung. Stuttgart: J. B. METZLER, 1983. p. 568-590.

SINHA, C. Language as a biocultural niche and social institution. In: EVANS, V. (Org.) New directions in cognitive linguistics. Philadelphia: J.Benjamins Co. 2009.

ZUMTHOR, Paul (1987). A letra e a voz - A "literatura" medieval. São Paulo: Cia das Letras, 1993.

ZUMTHOR, Paul. Escritura e nomadismo. São Paulo: Ateliê Editorial, 2005.

\section{ANEXO A \\ Tabela de símbolos}

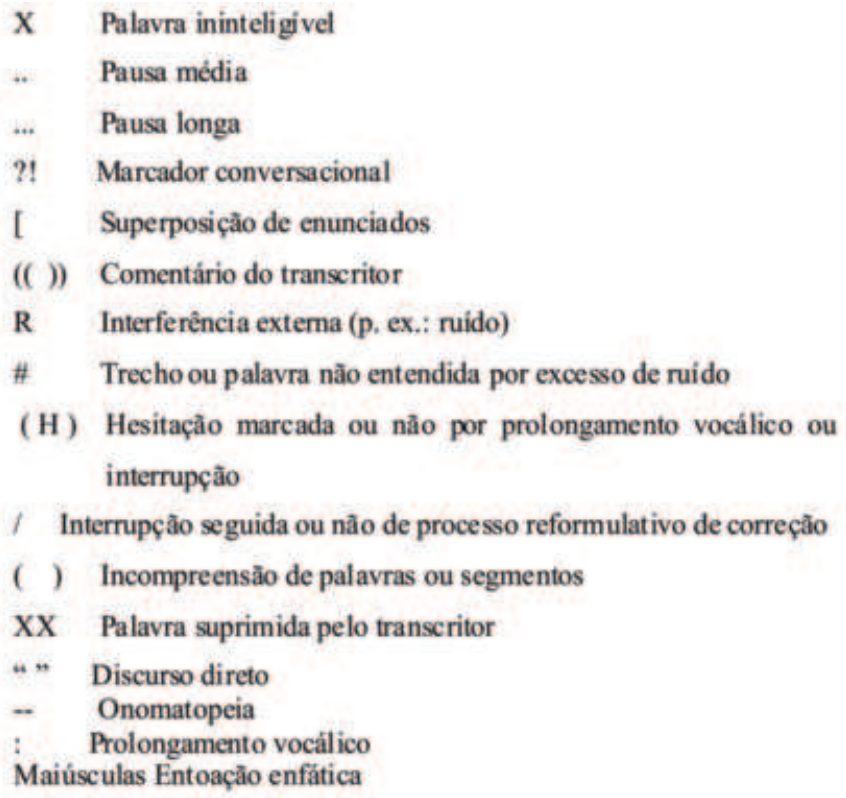

Data de submissão: 28/11/2012

Data de aprovação: 29/01/2013 